\title{
Influences of Short-Chain Fatty Acids on the Digestive Organs
}

\author{
Takaji Yajima and Takashi Sakata \\ Yakult Central Institute for Microbiological Research, 1796 Yaho, Kunitachi, Tokyo 186
}

(Received 21 Octobcr, 1986)

\begin{abstract}
Acetic, propionic, and $n$-butyric acids, called short-chain fatty acids (SCFA), are the major end-products of the hindgut fermentation. SCFA are rapidly absorbed across the colonic mucosa and used as the nutrient. Luminal SCFA enhance the absorption of sodium and water. Bicarbonate accumulates in the hindgut lumen in proportion to the amount of SCFA absorbed in various animals. The buffering system of the bicarbonate accumulated into the lumen in response to SCFA absorption may stabilize the luminal $\mathrm{pH}$. Propionic and $n$-butyric acids stimulate the colonic motility with an increased peristaltic propulsion of perfusate in the rat in vivo. Propionic, $n$-butyric, and $n$-valeric acids stimulate contractile response of the isolated segments of the rat colon in a dose-dependent manner. The contractile effect of SCFA on the rat colon does not act directly on the smooth muscle. The enteric nervous system may mediate the effect of SCFA, since the contractile responses were abolished by tetrodotoxin and atropine. The acute and chronic administration of SCFA (acetic, propionic, and $n$-butyric acid) into the hindgut of the rat enhanced the proliferation of the epithelium of the digestive tract in vivo. The stimulatory effect of SCFA is dose-dependent and is strong in order of $n$-butyric $>$ propionic $>$ acetic acids. Thus, SCFA are important not only as the nutrient but also as the modulator of electrolyte transport, motility, and epithelial proliferation of the digestive tract.
\end{abstract}

Key words: Electrolyte transport; motility; cpithclial proliferation; gut fermentation; luminal chemical stimuli

Acetic, propionic, and $n$-butyric acids, called short-chain fatty acids (SCFA) or volatile fatty acids (45), are the major endproducts of anaerobic microbial digestion of carbohydrates in the large intestine. Undigested fiber in the ileal effluent, mucin from the gastrointestinal mucosa, and desquamated cells are major sources of such fermentation $(6,38)$. SCFA $(100-200 \mathrm{mmol} /$ liter) constitute the major anion in the contents of the large intestine (45). SCFA can easily penetrate the luminal membrane of the epithelial cell in the large intestine as mostly un-ionized form (45).

A part of SCFA, especially butyrate, are metabolized in epithelial cells (27) with the residual part to be transported from the cells into the portal vein (45). SCFA absorbed from the large intestine serve as the energy source in various mammals; $5-30 \%$ in pigs, $5-9 \%$ in humans and rats (24).

In addition to such nutritional importance, SCFA affect gastrointestinal functions in various mammals (Table 1). Thus these acids seem to play an important role as the physiological luminal stimuli that modify the structure and function of digestive organs. The aim of this paper is to review recent findings on the absorption of SCFA and the influences of SCFA on the electrolyte transport, motility, and epithelial proliferation in the large intestine. 
Table 1. Physiological effects of short-chain fatty acids on the gastrointestinal organs of mammals

\begin{tabular}{|c|c|c|c|c|c|}
\hline Target organ & Animal & SCFA & $\begin{array}{c}\text { Site of } \\
\text { application }\end{array}$ & Physiological effect & References \\
\hline \multirow[t]{2}{*}{ Parotid gland } & Sheep & $\mathrm{C} 4$ & Rumen & Salivary secretion $\searrow$ & 23 \\
\hline & Sheep & $\mathrm{C} 2$ & Vein & Salivary secretion $\nearrow$ & 23 \\
\hline \multirow[t]{2}{*}{ Stomach } & Sheep & $\mathrm{C} 2-\mathrm{C} 4$ & Lumen & Motility & 5,20 \\
\hline & Sheep & $\mathrm{C} 2-\mathrm{C} 4$ & Lumen & Epithelial growth $\nearrow$ & $31-33,35,37$ \\
\hline \multirow{3}{*}{$\begin{array}{l}\text { Pancreatic } \\
\text { endocrine } \\
\text { gland }\end{array}$} & Sheep & & & & \\
\hline & Goat & $\mathrm{C} 2-\mathrm{C} 6$ & Vein & Hormone secretion $\nearrow$ & 14,21 \\
\hline & Cattle & & & & \\
\hline \multirow{2}{*}{$\begin{array}{l}\text { Pancreatic } \\
\text { exocrine gland }\end{array}$} & Vole & $\mathrm{C} 2-\mathrm{C} 8$ & Vein & Enzyme secretion $\nearrow$ & $11-13,15$ \\
\hline & Sheep & & & $\begin{array}{c}\text { Depolarization of } \\
\text { membrane } \nearrow\end{array}$ & 15,16 \\
\hline \multirow[t]{3}{*}{ Jejunum and ileum } & Rat & $\mathrm{C} 4$ & Lumen & $\begin{array}{l}\text { Discharge of vagus } \\
\text { nerve } \nearrow\end{array}$ & 4 \\
\hline & Rat & $\mathrm{C} 2-\mathrm{C} 6$ & Vein & Motility $\nearrow$ & 40 \\
\hline & Rat & C3-C6 & Vein & $\begin{array}{l}\text { Transmural potential } \\
\text { difference } \nearrow\end{array}$ & 43 \\
\hline Colon & Rat & $\mathrm{C} 3-\mathrm{C} 4$ & Vein & $\begin{array}{l}\text { Transmural potential } \\
\text { difference } \nearrow\end{array}$ & 44 \\
\hline
\end{tabular}

\section{The Absorption of SCFA and Its Influence on Electrolyte Transport}

It has been believed that diarrhea due to carbohydrate-malabsorption is induced by the excessive osmosis of SCFA in the large intestine; this was based on the misunderstanding that SCFA are poorly absorbed from the colon (10). However, recent studies revealed that SCFA are rapidly absorbed across the colonic mucosa of various animals (1-3, 26, 28, 39) (Fig. 1). In monogastric animals $95-99 \%$ of the SCFA produced by

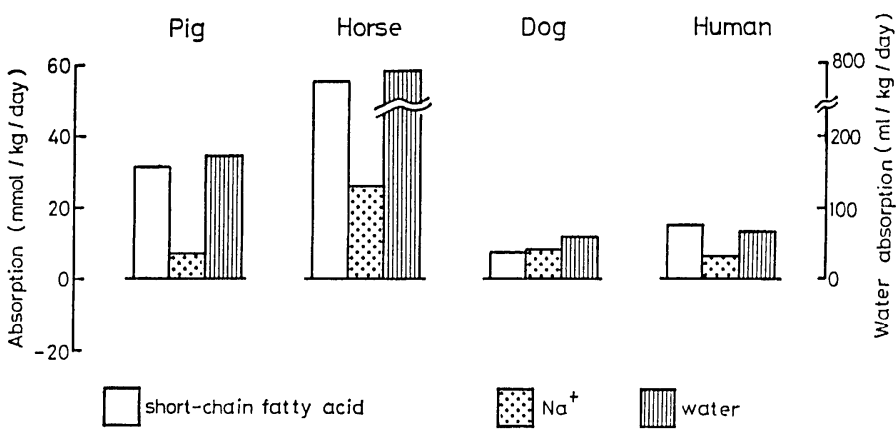

Fig. 1. In vivo absorption of short-chain fatty acids (SCFA), sodium and water by the large intestine of pig, horse, dog, and human. Proximal and distal segment of the pig large intestine was perfused separately. Ascending colon of the human was perfused by means of a multilumen perfusion tube. Bathing solutions were isotonic to the plasma of each species, but varied in composition. In the pig and human studies, SCFA consisted of only acetate and propionate, respectively. Drawn after the data in Argenzio et al. (1,3), Stevens et al. (36) and Ruppin et al. (28). 


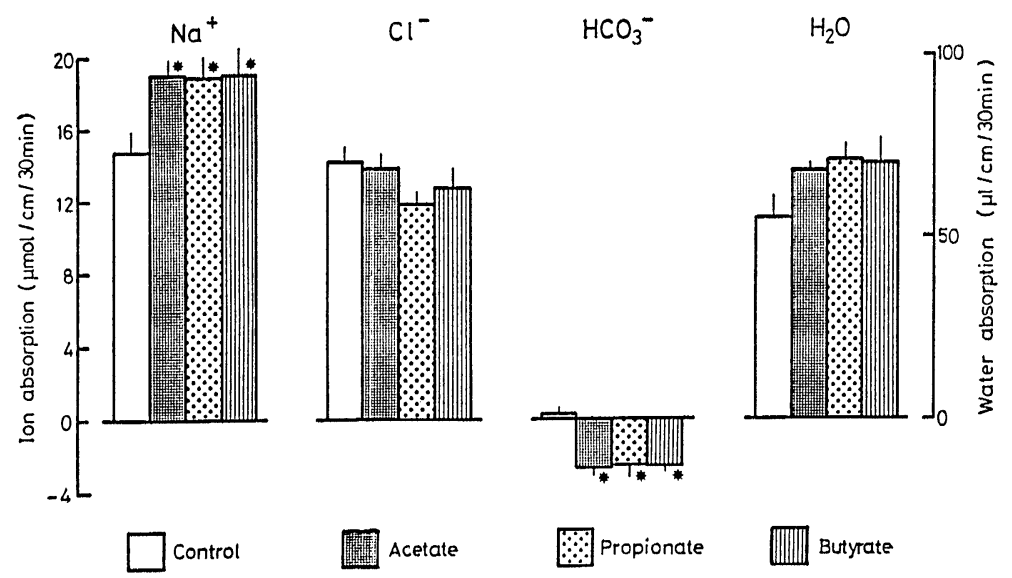

Fig. 2. The effects of SCFA on the water and electrolytes transport in rat colon. The whole colon was perfused in vivo with an isotonic solution containing $50 \mathrm{~mm}$ of each SCFA at the rate of $1 \mathrm{ml} / \mathrm{min}$. Values are expressed in mean \pm S.E. $(-)$ sign indicates net secretion. * Significantly different from the control $(p<0.05)$. Drawn after the data in Umesaki et al. (39).

the hindgut fermentation are absorbed from the large intestine (7). SCFA are absorbed faster than sodium on the molar basis. The luminal presence of SCFA normally accompanies water absorption.

Acetic, propionic, and $n$-butyric acids are more rapidly absorbed than lactic and succinic acids in an in vivo perfusion study in the rat (39). Luminal SCFA, but not lactic and succinic acids, enhance the absorptions of sodium and water (Fig. 2). Such enhancement of the sodium absorption by luminal SCFA are generally seen in guinea pigs (26), men (28), pigs (1), goats (2), and horses (3).

Although the large intestine is exposed to high concentrations of SCFA, the luminal $\mathrm{pH}$ in the cecum and the colon is maintained at a near-neutral range (6.5-7.0). Bicarbonate accumulates in the hindgut lumen in proportion to the amount of SCFA absorbed in rats (39), guinea pigs (26), men (28), goats (2), and horses (3). Umesaki et al. (39) demonstrated in an in vivo perfusion study of rats that a close linear relationship exists between the amount of SCFA absorbed and that of bicarbonate accumulated in the lumen (Fig. 3). Lactate and succinate do not cause the luminal accumulation of bicarbonate. Bicarbonate neutralizes the proton

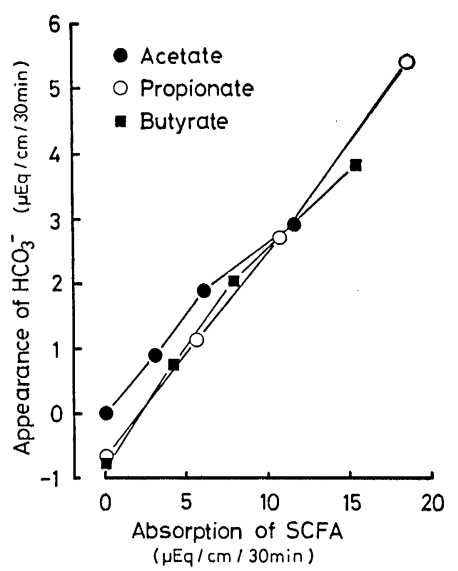

Fig. 3. Interrelationship between the absorption of SCFA and the appearance of bicarbonate in the lumen of rat colon in vivo. Various initial concentrations of SCFA were perfused. Values are expressed in mean \pm S.E. Drawn after the data in Umesaki et al. (39).

from SCFA as follows: $\mathrm{HCO}_{3}{ }^{-}+\mathrm{RCOOH} \rightarrow$ $\mathrm{RCOO}^{-}+\mathrm{H}_{2} \mathrm{O}+\mathrm{CO}_{2}$. Indeed, when the colon of rats is perfused by solutions $(\mathrm{pH}$ 5.7-5.8) with acetic or lactic acid, or without acid (control), the acetate-solution is neutralized faster than the lactate- or the control-solution (Y. Umesaki and T. Yajima, unpublished observation) (Fig. 4). The buffering system of the bicarbonate secreted 


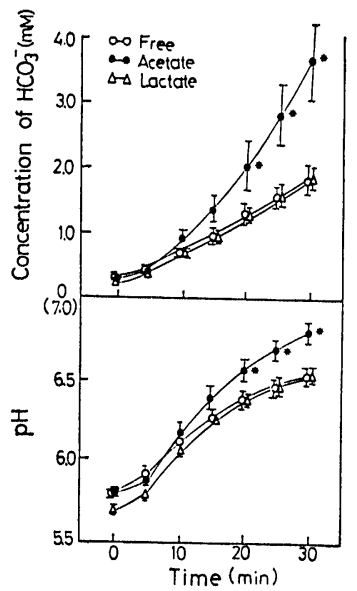

Fig. 4. The effect of bicarbonate appearance on luminal $\mathrm{pH}$ in an in vivo perfusion study of the rat colon. The solution contained $50 \mathrm{~mm}$ of acetate or lactate. Values are expressed in mean \pm S.E. * Significantly different from the control $(p<0.05)$ (Y. Umesaki and T. Yajima, unpublished observations).

into the lumen in response to SCFA absorption may stabilize the luminal $\mathrm{pH}$, thereby facilitating the establishment of a stable microbial ecosystem.

\section{Influence of SCFA on the Colonic Motility}

The luminal SCFA inhibit the reticuloruminal motility in the ruminant through the stimulation of a specific receptive mechanism in the mucosa of the reticulo-rumen $(18,19)$. The inhibitory reflections produced by the SCFA stimuli are mediated by the enteric nervous system (9) and/or the gastric center of the medulla oblonyata (18).

On the contrary, propionic and $n$-butyric acid $(10 \mathrm{~mm})$ stimulate the colonic motility with an increased peristaltic propulsion of perfusate in the rat in vivo (42) (Fig. 5). Propionic, $n$-butyric, and $n$-valeric acids stimulate contractile response of middle and distal, but not proximal, segments of the colon in rats (41) (Fig. 6). The contractile response began within $10 \mathrm{sec}$ after the application of SCFA and faded to the basal tone within $60 \mathrm{sec}$. The threshold concentration of SCFA in this contractile response was

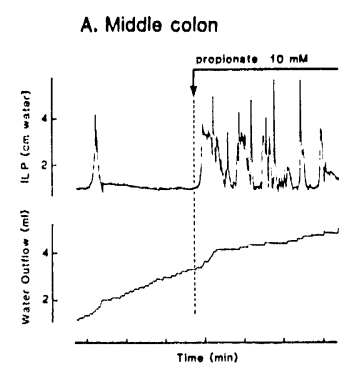

B. Distal colon

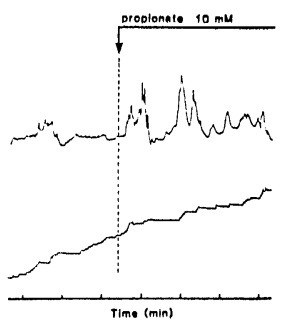

Fig. 5. The effect of propionate on the motility and water outflow in rat colonic loops perfuscd orthodromically in vivo. The motility was estimated as changes in the intraluminal pressure (ILP) and the water outflow was monitored with a volume recorder. The initial intraluminal pressure on each loop was set at $4 \mathrm{~cm}$-water high. Drawn after the data in Yajima ct al. (42).

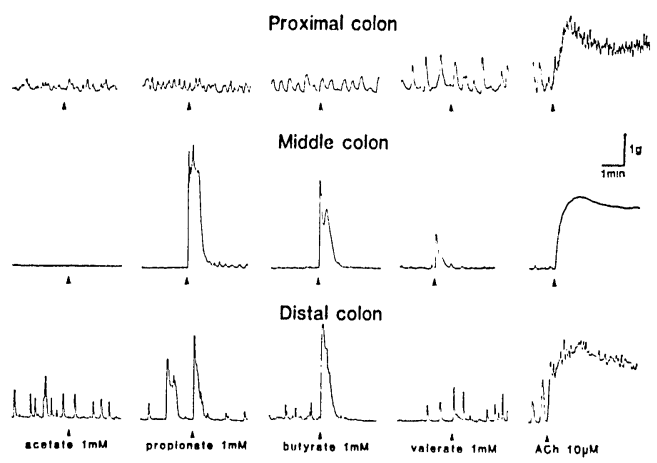

Fig. 6. The effects of SCFA on the contraction of the three colonic segments of the rat in vitro. The longitudinal mechanical activity in the $10 \mathrm{ml}$-organ bath at $37^{\circ} \mathrm{C}$ was recorded isometrically with a force transducer and a polygraph. The everted segments were used to exert SCFA-stimuli from the mucosal side. The SCFA concentrations indicated refer to the final molarity in the organ bath. Drawn after the data in Yajima (41).

$0.03 \mathrm{~mm}$ for the middle and distal colon and the maximal response was attained at $0.1 \mathrm{~mm}$. Acetic (10 mm) and lactic (30 mm) acid had no contractile effect on the rat colon.

The contractile effect of SCFA on the rat colon does not act directly on the smooth muscle, since SCFA do not stimulate the contraction of the isolated colonic muscle layer but relax it. The enteric nervous system 
may mediate the effect of SCFA, since the contractile responses were abolished by tetrodotoxin (a neuroblocker) and atropine (a muscarinic receptor antagonist). A sensory mechanism for SCFA seems to exist at or near the mucosa, since both (A) the scraping of the mucosa abolished the response, and (B) a pretreatment with procaine (a local anesthetic) added to the mucosal surface inhibited the contractile response to propionate, suggesting the presence of a sensory mechanism for SCFA within or near the epithelium. The short latency $(<10 \mathrm{sec})$ suggests that the receptive mechanism (receptor) for SCFA may exist somewhere in or just beneath the epithelium in the rat colon.

The possible presence of SCFA-receptor is supported by the indirect evidences of (A) reversible self- and cross-adaptations elicited by propionate, $n$-butyrate, and $n$-valerate, and (B) the apparent antagonism exerted by acetate and lactate (Fig. 7).

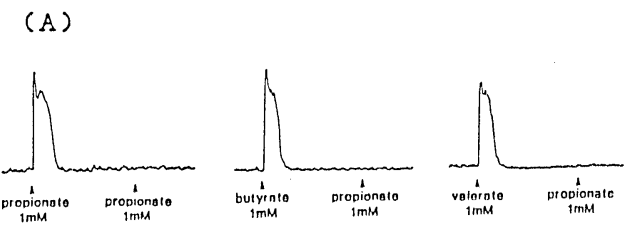

(B)

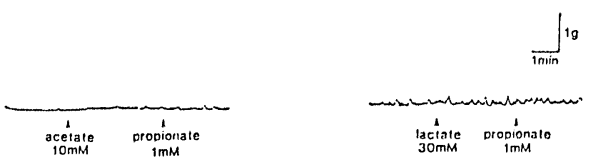

Fig. 7. (A) the self- and cross-desensitization produced by the cumulative addition of propionate, $n$-butyrate, or $n$-valerate, and (B) the cross-adaptation produced between acetate or lactate, and propionate. The longitudinal mechanical activity was recorded as similar as in Fig. 6. The everted preparations from the middle colon were used. The same or a different acid was cumulatively applied after an interval of about $4 \mathrm{~min}$. Drawn after the data in Yajima (41).

\section{Influence of SGFA on the Epithelial Cell Division of the Digestive Tract}

SCFA generally inhibit the proliferation of mammalian cells in vitro $(17,25)$, including the primary culture of ruminal epithelium (8). Sakata (29) demonstrated that acetic, propionic, and $n$-butyric acids inhibit cryptal cell proliferation rate of isolated cecum cultured in vitro for a short time, in a dosedependent manner. The strength of the inhibitory effect was in the order of $n$-butyrate $>$ propionate $>$ acetate.

On the contrary, SCFA stimulate the cell proliferation of the epithelium of the digestive tract in vivo (30). SCFA are responsible for the drastic development of the ruminant forestomach mucosa during the weaning period (37). Sakata and Engelhardt (30) demonstrated that a solution of physiological concentration of SCFA (acetic acid $75 \mathrm{~mm}$,

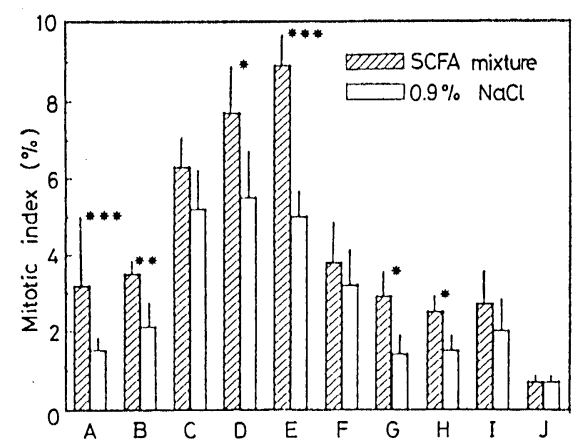

Fig. 8. The effect of SCFA on the various epithelial proliferations in the rat in vivo. Mean epithelial mitotic index of the esophagus (A), nonglandular region of the stomach (B), duodenum (C), jejunum (D), cecum $(\mathbf{F})$, proximal colon without direct contact to SCFA (G), proximal colon exposed to SCFA $(\mathrm{H})$, distal colon $(\mathrm{I})$, and ear epidermis (J) of rats perfused with SCFA mixture (acetate, 75; propionate, 35 ; and $n$-butyrate, $20 \mathrm{~mm}$ ) into the colon. Results were compared to those for colonic perfusion of $0.9 \%$ saline. Vertical bars show the S.D. $(n=4)$. ***, $* *$, $*$ Significantly different from the saline control $(p<0.001,0.01$ and 0.05 , respectively). Drawn after the data in Sakata and Yajima (34). 
propionic acid $35 \mathrm{~mm}, n$-butyric acid $20 \mathrm{~mm}$ ) introduced into the temporary isolated loop in the proximal colon of the rat in vivo stimulated the epithelial proliferation not only in the colon but also in intestinal segments without any direct contact to SCFA (Fig. 8). A bilateral surgical vagotomy at the fundic level or a chemical sympathectomy with guanethidine abolished the stimulatory effects of SCFA, indicating the possible involvement of the autonomic nervous system in this effect.

In addition to the acute effect of SCFA on the proliferation of gut epithelium, Sakata (29) demonstrated that the chronic administration of SCFA (acetic acid $100 \mathrm{~mm}$, propionic acid $20 \mathrm{~mm}$, and $n$-butyric acid $60 \mathrm{~mm}$, mixed solution, $3 \mathrm{ml} \times 2 /$ day) into the hindgut of the rat via the ileostomy enhanced the proliferation of colonic epithelium within 2 days and it lasted for at least 14 days. The stimulatory effect of SCFA is dose-dependent and is strong in order of $n$-butyric $>$ propionic $>$ acetic acids. Such effect of SCFA is not due to low luminal $\mathrm{pH}$.

\section{Physiological Significance of SCFA Stimuli}

In the foregut the luminal nutrients, such as glucose, amino acids and higher fatty acids which are the enzymatic digestive products of foods, cause stimulation or inhibition of gastric and pancreatic secretions, and changes in motility, circulation, and absorption (22). These changes in the gastrointestinal functions may be due to autonomic and/ or enteric reflexes originating from the mucosal chemosensitive receptors.

On the other hand, we suggested in this article that SCFA being the microbial digestive products in the hindgut work not only as nutrients but also as the luminal stimuli for the colonic absorption and motility and the gastrointestinal epithelial proliferation. SCFA-stimuli may be mediated by the mucosal receptors in the hindgut.

Thus the chemical stimuli from the gastrointestinal lumen are one of the factors regulating the functions and structure of the digestive organ. SCFA seem to transmit the message from microbes in the hindgut to the host animal.

\section{Conclusion}

Symbiosis between animals and the microbes in the large intestine seems to be, at least in part, accomplished by nutritional and physiological actions of SCFA. SCFA are important not only as the nutrient but also as the modulator of electrolyte transport, motility, and epithelial proliferation. The rapid absorption of SCFA accompanying the absorptions of sodium and water from the large intestine are probably important for the systemic balance of water and electrolytes. The stimulatory effect of SCFA on the propulsive motility in the middle and distal segments of the rat colon may be related to the propulsion of feces. The stimulatory effects of SCFA on the gastrointestinal epithelial proliferation are considered as a nutritional adaptive response of mucosa to the hindgut fermentation.

\section{References}

(1) Argenzio, R.A., and S.C. Whipp. 1979. Intcrrelationship of sodium, chloride, bicarbonate and acetate transport by the colon of the pig. J. Physiol. 295: 365-381.

(2) Argenzio, R.A., N. Miller, and W.v. Engclhardt. 1975. Effect of volatile fatty acids on water and ion absorption from the goat colon. Am. J. Physiol. 229: 997-1002.

(3) Argenzio, R.A., M. Southworth, J.E. Lowe, and C.E. Stevens. 1977. Interrelationship of $\mathrm{Na}$, $\mathrm{HCO}_{3}$ and volatile fatty acid transport by equinc large intestine. Am. J. Physiol. 233: E469-478.

(4) Clarke, G.D., and J.S. Davison, 1978. Mucosal receptors in the gastric antrum and small intestine of the rat with afferent fibres in the cervical vagus. J. Physiol. 284: 55-67.

(5) Cottrell, D.F., and A. Iggo. 1984. Tension receptors with vagal afferent fibres in the proximal duodenum and pyloric sphincter of sheep. J. Physiol. 354: 547-475.

(6) Cummings, J.H. 1981. Dietary fiber. Br. Med. Bull. 37: 65-70.

(7) Engelhardt, W.v., and G. Rechkemmer. 1982. The physiological effects of short-chain fatty 
acids in the hind gut, p. 149-155. In G. Wallace and L. Bell (eds.), Fiber in human and animal nutrition, The Royal Society of New Zealand, Wellington.

(8) Galfi, E., T. Versegyhazy, S. Neogrady, and F. Kutas. 1981. Effect of sodium $n$-butyrate on primary ruminal epithelial cell culture. Z. Vet. Med. A28: 259-261.

(9) Gregory, P.C. 1984. Control of intrinsic reticuloruminal motility in the vagotomized sheep. J. Physiol. 346: 379-393.

(10) Grove, E.W. 1929/1930. The effect of diet and catharsis on the lower volatile fatty acids in the stools of normal man. J. Biol. Chem. 85: 127-136.

(11) Harada, E. 1983. Exocrine pancreatic secretion in Microtus montebelli. Proc. Jap. Soc. Vet. Sci. $96: 54$.

(12) Harada, E. 1983. Effects of short-chain fatty acids on the exocrine secretion of mice pancreas. Proc. Jap. Soc. Vet. Sci., p. 49 (in Japanese).

(13) Harada, E., and S. Kato. 1983. Effects of short chain fatty acids on the secretory response of the ovine exocrine pancreas. Am. J. Physiol. 244: G284-G290.

(14) Horino, M., J. Machlin, F. Hertelendy, and D.M. Kipnis. 1968. Effect of short-chain fatty acids on plasma insulin in ruminant and nonruminant species. Endocrinology 83: 118-128.

(15) Katoh, K., and T. Tsuda. 1984. Effects of acetylcholine and short-chain fatty acids on acinar cells of the exocrine pancreas in sheep. J. Physiol. 356: 479-478.

(16) Katoh, K., and T. Tsuda. 1985. Effects of secretagogues on membrane potential and input resistance of pancreatic acinar cells of sheep. Res. Vet. Sci. 38: 250-251.

(17) Kruh, J. 1982. Effects of sodium butyrate, a new pharmacological agent, on cells in culture. Mol. Cell. Biochem. 42: 65-82.

(18) Leek, B.F. 1969. Reticulo-ruminal mechanoreceptors in sheep. J. Physiol. 202: 585-609.

(19) Leek, B.F. 1986. Sensory receptors in the ruminant alimentary tract. p. 3-17. In L.P. Milligan, W.L. Grovum and A. Dobson (eds.), Control of digestion and metabolism in ruminants, A Reston Book, Engelwood Cliffs.

(20) Leek, B.F., and R.H. Harding. 1975. Sensory nervous receptor in the ruminant stomach and the reflex control of reticuloruminal motility, p. 60-76. In I.W. McDonald and A.C.I. Warner (eds.), Digestion and metabolism in the ruminant, University of New England Publishing Unit, Armidale.

(21) Manns, J.G., and J.M. Boda. 1967. Insulin release by acetate, propionate, butyrate, and glucose in lambs and adult sheep. Am. J. Physiol. 212: 747755.

(22) Mei, N. 1986. Intestinal chemosensitivity. Physiol. Rev. 65 : 211-237.
(23) Obara, Y., Y. Sasaki, S. Watanabe, and T. Tsuda. 1972. The effects of the intravenous infusion of volatile fatty acid on the parotid secretion of sheep. Tohoku J. Agric. Res. 23: 141-148.

(24) Parra, R. 1978. Comparison of foregut and hindgut fermentation in herbivores, p. 205--229. In G. Montogomery (ed.), The ecology of arboreal folivores, Smithsonian Institution Press, Washington, D.C.

(25) Prasad, K.N. 1980. Butyric acid: a small fatty acid with diverse biological functions. Life Sci. 27 : 1351-1358.

(26) Rechkemmer, G., and W.v. Engelhardt. 1982. Absorptive processes in different colonic segments of the guinea pig and the effects of short-chain fatty acids, p. 61-67. In H. Kasper and H. Goebell (eds.), Colon and nutrition, MTP Press, Lancaster.

(27) Roediger, W.E.W. 1981. The effect of bacterial metabolites on nutrition and function of the colonic mucosa. Symbiosis between man and bacteria, p. 11-24. In $\mathrm{H}$. Kasper and $\mathrm{H}$. Goebell (eds.), Colon and nutrition, MTP Press, Lancaster.

(28) Ruppin, H., S. Bar-Meir, H. Soergel, C.W. Wood, and M.G. Schmitt, Jr. 1980. Absorption of short-chain fatty acids by the colon. Gastroenterology 77: 658-663.

(29) Sakata, T. 1987. Stimulatory effect of short chain fatty acids on epithelial cell proliferation in the rat intestine: a possible explanation for trophic effects of fermentable fibre, gut microbes and luminal trophic factors. Br. J. Nutr. (in press).

(30) Sakata, T., and W.v. Engelhardt. 1983. Stimulatory effect of short-chain fatty acids on the epithelial cell proliferation in rat large intestine. Comp. Biochem. Physiol. A47: 459-462.

(31) Sakata, T., and H. Tamate. 1978. Rumen epithelial cell proliferation accelerated by rapid increase in intraruminal butyrate. J. Dairy Sci. 61: 1109-1113.

(32) Sakata, T., and H. Tamate. 1978. Influence of butyrate on micrscopic structure of ruminal mucosa in adult sheep. Jpn. J. Zootech. Sci. 49: 687-696.

(33) Sakata, T., and H. Tamate. 1979. Rumen epithelium cell proliferation accelerated by propionate and acetate. J. Dairy Sci. 62: 49-52.

(34) Sakata, T., and T. Yajima. 1984. Influence of short-chain fatty acids on the epithelial cell division of digestive tract. Q. J. Exp. Physiol. 69: 639-648.

(35) Sander, E.G., R.G. Warner, H.N. Harrison, and J.K. Loosli. 1959. The stimulatory effect of sodium butyrate and sodium propionate on the development of rumen mucosa in the young calf. J. Dairy Sci. 42: 1600-1605.

(36) Stevens, C.E., R.A. Argenzio, and E.T. Clemens. 1980. Microbial digestion: rumen versus large 
intestine, p. 685-706. In Y. Ruckebisch and P. Thivend (eds.), Digestive physiology and metabolism in ruminants, MTP Press, Lancaster.

(37) Tamate, H., A.D. McGilliard, A.D. Jacobson, and R. Getty. 1964. The effect of various diets on the histological development of the stomach of the calf. Tohoku J. Agric. Res. 14: 171-193.

(38) Topping, D.L. and R.J. Illman. 1986. Bacterial fermentation in the human large bowel. Med. J. Aust. 144: 307-309.

(39) Umesaki, Y., T. Yajima, T. Yokokura, and M. Mutai. 1979. Effect of organic acid absorption on bicarbonate transport in rat colon. Pflügers Arch. 379: 43-47.

(40) Yajima, T. 1984. Effect of sodium propionate on the contractile response of the rat ileum in situ. Jpn. J. Pharmacol. 35: 265-271.

(41) Yajima, T. 1985. Contractile effect of short-chain fatty acids on the isolated colon of the rat. J.
Physiol. 368: 667-678.

(42) Yajima, T., H. Hijikata, and T. Sakata. 1983. Contractile response of rat colon to short-chain fatty acids. Proc. Jap. Soc. Vet. Sci., p. 29 (in Japanese).

(43) Yajima, T., K. Kojima, K. Tohyama, and M. Mutai. 1981. Effect of short-chain fatty acids on electrical activity of the small intestinal mucosa of rat. Life Sci. 28: 983-989.

(44) Yajima, T., K. Kojima, K. Tohyama, and M. Mutai. 1982. Alteration in sensitivity of transmural electrical response to propionate in rat colon after chronic luminal infusion of shortchain fatty acids. Life Sci. 32: 1073-1079.

(45) Wrong, O.M., C. J. Edmonds, and V.S. Chadwick. 1981. The large intestine: its role in mammalian nutrition and homeostasis, MTP Press, Lancaster. 